\title{
The allure of salt
}

\author{
JAY SCHULKIN \\ University of Pennsylvania, Philadelphia, Pennsylvania
}

\begin{abstract}
The allure of salt may have its roots in the innate hunger for sodium. And this innate hunger for sodium may play a role in several mineral deficiencies, because sodium is also ingested when rats are deficient in other minerals. Perhaps, the mineral-deficient animal ingests the sodium because of the taste quality of saltiness. An adaptive strategy that may have evolved is to have saltiness serve as a marker for minerals in the behavioral restoration of mineral balance; in other words, this taste quality may signal that minerals may be found at a particular location and may serve as an important vehicle in nutritional memory. This adaptive strategy may be particularly important for females who frequent salt licks during the reproductive season when there is a greater demand for minerals. It is the taste quality of saltiness that may stand out for the mineral-deficient animal.
\end{abstract}

The search for and identification and ingestion of salt is one of the most investigated examples of how gustatory capability interacts with regulatory demands. The behavior is mediated by a specific gustatory sodium pathway. There is perhaps no better example in the literature of a gustatory category (the taste of something salty) impacting the regulation of ingestive behavior - that is, the ingestion of sodium in the sodium-deficient animal (see review by Schulkin, 1991). Other ingestive responses to mineral or vitamin deficiencies do not appear to use a specific gustatory taste quality in the identification of what is needed by the body the way sodium does (Rozin $\&$ Schulkin, 1990). In addition, the regulation of sodium demonstrates the close relationship between the state of sodium hunger and the hedonic shift in the perception of concentrated $\mathrm{NaCl}$ (Berridge, Flynn, Schulkin, \& Grill, 1984).

Consider a hypothesis explaining why the gustatory quality of saltiness is alluring. The two theses of this paper are (1) that the innate hunger for sodium organizes other mineral hungers (i.e., the search for sodium may lead to the ingestion of minerals other than sodium), and (2) that the psychophysical taste property of saltiness serves as a gustatory marker for minerals.

\section{The Innate Hunger for Sodium}

It is well known that the very first time rats or sheep are sodium-hungry, they ingest sodium salts within seconds upon their exposure to them (Denton, 1982; Wolf, 1969). Other mineral deficiencies do not, for the most part, result in this immediate ingestion of the required mineral (Rozin \& Schulkin, 1990). Moreover, in sodiumhungry animals, the taste of salt becomes more reward-

This research was supported by Research Career Development Award 00678 from the National Institute of Mental Health and by NIMH Program Project Grant MH 43787. Correspondence should be addressed to Jay Schulkin, Department of Anatomy, University of Pennsylvania, Philadelphia, PA 19104-6018. ing (Schulkin, Arnell, \& Stellar, 1985); this change in the perception of salt appears to be innate (Berridge et al., 1984; Berridge \& Schulkin, 1989). Rats, for example, express a mixed oral-facial acceptance-rejection profile to intraorally infused concentrated $\mathrm{NaCl}$. This response is dramatically changed the very first time rats are rendered sodium-hungry; the facial display then becomes largely positive (Berridge et al., 1984; Berridge \& Schulkin, 1989). The effect was specific for the salty taste of $\mathrm{NaCl}$, since the rats did not show this shift to other taste qualities (like the sourness of citric acid or bitterness of quinine).

The neurophysiological evidence is also corroborative of a hedonic shift in the salt-hungry rat; there is a decrease in "salt-best" neuronal activity at the level of the 7th nerve and at the level of the solitary nucleus (e.g., Contreras, Kosten, \& Frank, 1984; Hill, 1988; Jacobs, Mark, \& Scott, 1988). In the sodium-hungry rat, the sweet- or reward-best neurons of the solitary nucleus increase their firing pattern to infused $\mathrm{NaCl}$ (Jacobs et al., 1988). That is, the aversiveness of concentrated $\mathrm{NaCl}$ is decreased in the sodium-hungry animal, and its positiveness is increased. This is reflected at both behavioral and neurophysiological levels of analysis.

Rats are also innately able to recognize where salt is located, how to obtain it, and what other taste qualities it is associated with when they are sodium-replete. We know this because the very first time they are rendered sodium-hungry they return to the place where $\mathrm{NaCl}$ was last located (Krieckhaus, 1970; Paulus, Eng, \& Schulkin, 1984), will perform operants to obtain the salt (e.g., Dickinson \& Nicholas, 1983a, 1983b; Krieckhaus \& Wolf, 1968), and will ingest substances that were previously associated with the $\mathrm{NaCl}$ (Fudim, 1978; Rescorla \& Freeburg, 1978). Just a brief exposure to the salt is sufficient to elicit this learning (Bregar, Strombakis, Allan, \& Schulkin, 1983; Hartzell, Paulus, \& Schulkin, 1985; Wirsig \& Grill, 1982). Moreover, the taste qualities that were associated with sodium when the rats were sodiumreplete can be rendered positive (measured by the oral- 
facial profile) when sodium-hungry rats are infused with them into the oral cavity (Berridge \& Schulkin, 1989). Rats, at least, are not only prepared to recognize where salt is and how to obtain it, but they are also able to recognize and record other taste properties associated with it. This is important because in nature, as opposed to the laboratory, taste qualities are usually composite and varied.

In nature, a set of taste qualities is known to be perceived, at least by humans, at salt composites (Jones \& Hanson, 1985). Perhaps, the saltiness of $\mathrm{NaCl}$ is the important gustatory marker of the mineral. As noted above, when sodium-replete, animals notice and encode sources of sodium and associated taste qualities. When sodium is needed, they call on these memories. Perhaps Shakespeare was right when he referred to the saltiness of time: salty tastes are tied to memory. Rats that are sodium-hungry for the first time and that have been taught to barpress for salts will barpress much more if they have been trained with sodium salts, as was found in the classic Krieckhaus and Wolf (1968) experiment. However, if one waits 8 days before testing them, instead of 1 day, then the sodium-hungry rats barpress about the same for both $\mathrm{NaCl}$ and $\mathrm{KCl}$ salts (Dickinson \& Nicholas, 1983a, 1983b). One hypothesis is that what they remember is saltiness. The other taste properties of the $\mathrm{KCl}$ (e.g., its chalkiness) no longer stand out; now, it is remembered as $\mathrm{NaCl}$. And thus they barpress more vigorously.

\section{Salt Licks and Salt Ingestion}

Many animals in the wild are known to search for and then ingest salt at salt licks. It is a common occurrence in ungulates, in particular, migrating great distances to ingest salt (e.g., elk, reindeer, and moose). Experimental evidence has demonstrated that several species (e.g., rabbits and kangaroos) that are grazing on sodium-diluted food sources will ingest pegs of sodium salts (Denton, 1982). The attraction to salt has also been found in primates (e.g., gorillas or chimpanzees are known to eat dirt rich with minerals; see review by Schulkin, 1991). Even carnivores, such as the fox, have been noted for their ingestion at salt licks (Denton, 1982). The phenomenon is not confined only to mammals. Several species of birds (e.g., finches) are also known to lick at salt licks (Aldrich, 1939; Peterson, 1942).

In the laboratory, sodium-hungry rats (Schulkin, Amell, \& Stellar, 1986) or sheep (Denton, 1982) will regulate their sodium requirements by the ingestion at salt licks. In an experiment to examine salt-ingestive behavior, we adrenalectomized $2250-\mathrm{g}$ male Sprague-Dawley rats, and 2 rats remained as controls. All rats were anesthetized by i.m. injection of ketamine $(40 \mathrm{mg} / \mathrm{kg})$ and xylazine $(13 \mathrm{mg} / \mathrm{kg})$ and administered a prophylactic dose of gentamicin. In 2 of the rats, the adrenals were visualized through bilateral incisions made just posterior to the rib cage, the connective tissue between the adrenal gland was ligated, and the entire adrenal gland was then removed. In the 2 controis, everything but the adrenals was removed. Two days after surgery, a salt lick was placed in the front of the cage and weighed daily. Figure 1 depicts their intake on the first day and average over 150 days.

Females are often seen at the salt lick, and they go there during the reproductive season (Herbert \& Cowan, 1971). In the laboratory, it is well known that during pregnancy and lactation, salt intake in female rats, rabbits, and mice is further elevated (Denton, 1982; Richter, 1956). It has also been demonstrated in several species that virgin females have a greater avidity for salt than do males (e.g., Krecek, Novakova, \& Stibral, 1972; Sakai, Frankmann, Fine, \& Epstein, 1989; Schulkin, Leibman, Ehrman, Norton, \& Ternes, 1984), and female rats are known to
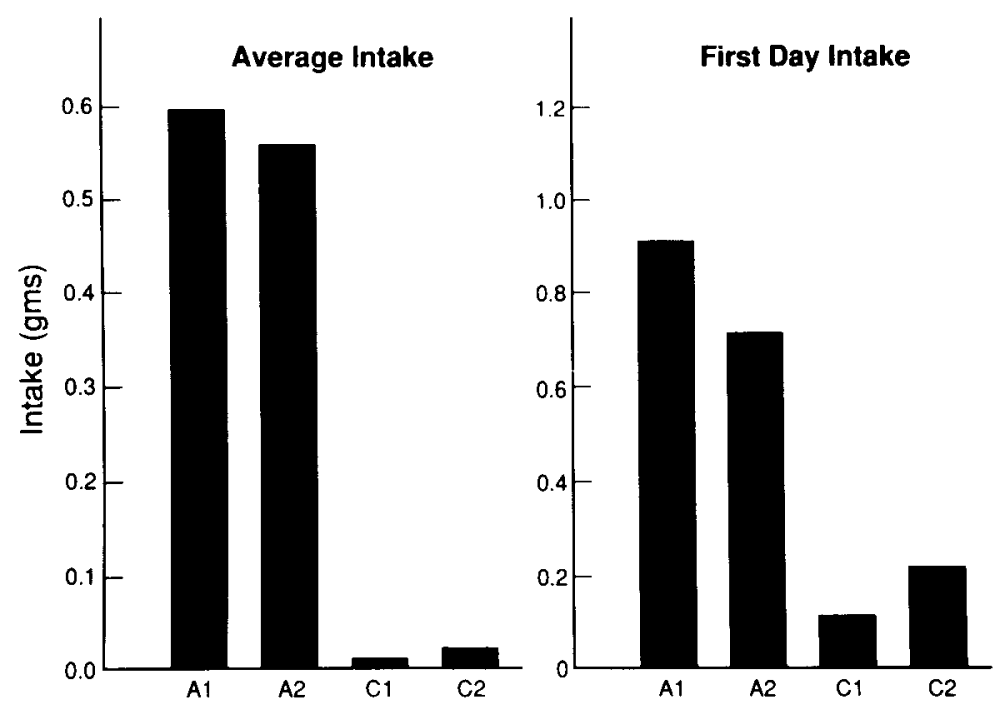

Figure 1. Ingestion of salt licks in adrenalectomized (A1, A2) and control (C1, C2) rats. 
run faster down a runway for $\mathrm{NaCl}$ rewards (Arnell, Schulkin, \& Stellar, 1988). Female rats also ingest more $\mathrm{NaCl}$ than males do to a variety of natriorexigenic treatments (e.g., Schulkin, 1991). The roots of this elevated salt intake in the female may lie in the demands that she faces during pregnancy and lactation. Perhaps, the greater avidity for the salty taste of sodium, in particular, draws the female to the salt lick; she may then satisfy her other mineral requirements. The one innate hunger for sodium, and the attractiveness of sodium, may be used to satisfy the other mineral demands at this time. Consider why this may be true.

It is important to note that several minerals are almost invariably present in salt licks (Jones \& Hanson, 1985). What taste property attracts the sodium- or mineral-hungry animal to the salt lick? We know that, in the laboratory, the only mineral that reveals a significant preferenceaversion ingestion curve is $\mathrm{NaCl}$ (e.g., Stellar, Hyman, \& Samet, 1954; Van Hemel, 1976); no other salt generates this function. Moreover, $\mathrm{NaCl}$ can taste sweet to humans, depending on the concentration of sodium that bathes the oral cavity (Bartoshuk, Murphy, \& Cleveland, 1978).

It is perhaps the saltiness of the sodium that triggers this attraction to salt licks. It is known, afterall, that $\mathrm{NaCl}$ captures something of what one means by a pure salty taste; all other salts taste less salty and/or have other taste properties (Bartoshuk, 1980; Schulkin, 1982). Even LiCl, which tastes very salty, is not perceived as producing what might be construed as the prototypical salty taste (Schulkin, 1982). This distinction is left for $\mathrm{NaCl}$.

When sodium-hungry rats are offered choices of salt solutions that humans have judged for their saltiness, they tend to prefer the more salty tasting (Figure 2). In an experiment that further demonstrates this phenomenon, 6 Sprague-Dawley rats, each weighing $250 \mathrm{~g}$, were placed on an Na-deficient diet (Teklad TD 81263) and given a 5-mg s.c. injection of furosemide to induce sodium loss

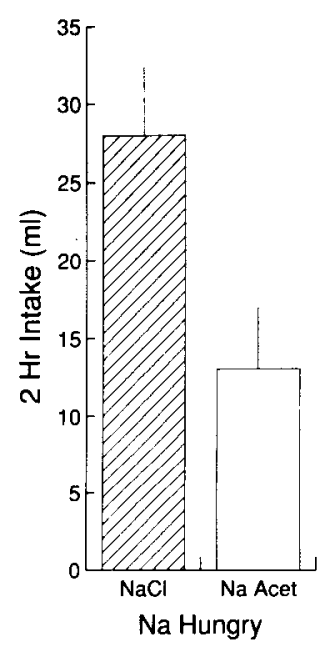

Figure 2. Ingestion of $.12 \mathrm{M} \mathrm{NaCl}$ and $.12 \mathrm{M} \mathrm{Na}$ acetate in sodiumhungry (acute sodium loss) rats.

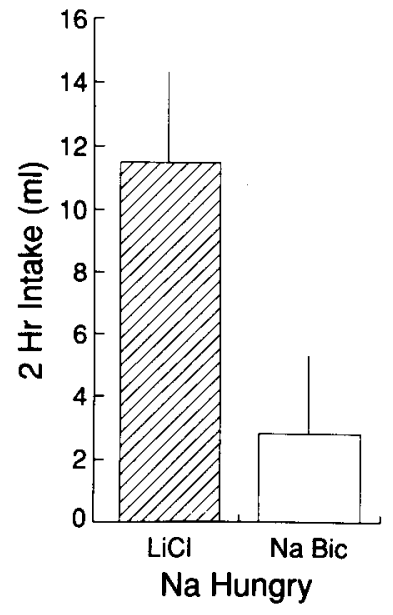

Figure 3. Ingestion of $.12 \mathrm{M} \mathrm{LiCl}$ and $.12 \mathrm{M} \mathrm{Na}$ bicarbonate in sodium-hungry (acute sodium loss) rats.

(see Wolf, 1982). Water was given ad lib. Twenty-four hours later, they were offered the two salt solutions, about $3 \mathrm{~h}$ into the light cycle of the 12:12-h light:dark cycle. To expose the rats to salt, it was gently touched to their mouths. The salt was then placed in the front of the cage in graduated cylinders. Intakes were measured at $2 \mathrm{~h}$, and the location of the cylinders was altered twice in the home cage in the first $10 \mathrm{~min}$ of the test (see Schulkin, 1982, for more details). $\mathrm{NaCl}$ is judged by humans to be more salty tasting than $\mathrm{Na}$ acetate, and it was ingested in greater amounts by the sodium-hungry rats $(p<.05)$, unpaired $t$ test; see also Schulkin, 1982).

It has been known for some time that sodium-hungry rats would ingest nonsodium salts such as $\mathrm{LiCl}$ to varying degrees (Falk, 1965; Jalowiec, Crapanzano, \& Stricker, 1966; Nachman, 1963; Schulkin, 1982). In addition, sodium-hungry rats will run faster down a runway for $\mathrm{LiCl}$ than for NaSaccharine. To humans, $\mathrm{LiCl}$ tastes saltier than NaSaccharine does (Schulkin et al., 1985). Figure 3 shows that, in an experiment with 8 new rats (and in conditions described above), sodium-hungry rats ingest the lithium salt to a greater degree than they ingest the sodium salt ( $p<.05$, unpaired $t$ test); the $\mathrm{LiCl}$ was judged more salty tasting by humans.

I also observed in 6 new sodium-hungry rats (as above) that they preferred potassium over calcium solutions (Figures 4 and $5 ; p<.05$, unpaired $t$ test); if one asks humans which of the two tastes saltier, they say the potassium does. None of these salts are ingested in significant amounts when Na-replete during this 2 -h test period. In other words, sodium-hungry rats in some contexts will ingest nonsodium salts and prefer the more salty-tasting solute when sodium-hungry (see also Schulkin, 1982).

What many of these nonsodium salts have in common is the taste property of saltiness. The sodium-hungry rats have an innate appetite to ingest something that tastes salty to them when sodium-hungry; they immediately ingest the sodium salts or lithium salts first because they taste salty, 


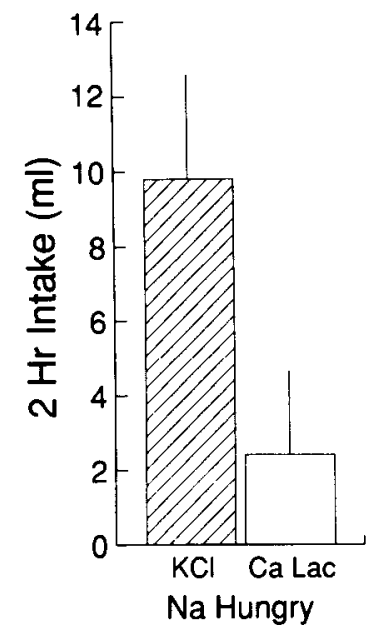

Figure 4. Ingestion of $.12 \mathrm{M} \mathrm{KCl}$ and $\mathrm{Ca}$ lactate in sodium-hungry (acute sodium loss) rats.

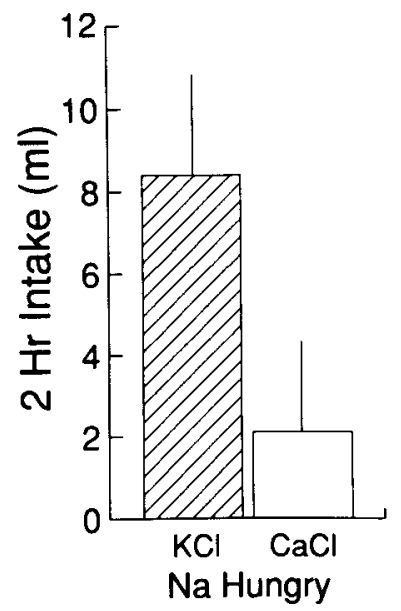

Figure 5. Ingestion of .12 $\mathrm{M} \mathrm{KCl}$ and $.12 \mathrm{CaCl}$ in sodium-hungry (acute sodium loss) rats.

and secondly because sodium-lithium-sensitive neurons in the chorda tympani nerve are importantly involved in this immediate recognition and ingestion of these salts (Nitabach, Spector, \& Grill, 1988). Perhaps, the 9th cranial nerve also mediates the perception of salt through the less specialized nonsodium salts, thus ensuring their ingestion over longer periods of time (Schulkin, 1991).

It is also the case that other mineral deficiencies result in sodium ingestion. For example, potassium deficiency results in sodium ingestion (Adam \& Dawborn, 1972; Blake \& Jurf, 1968; Schulkin, 1986). In this experiment, 16 Sprague-Dawley rats, each weighing $200 \mathrm{~g}$, were placed on a potassium-deficient diet (Teklad diet 88239 ) for 2 weeks. They were then offered the salts for the first time and placed at the front of their home cage (as described) at the beginning of the night cycle for up to $2 \mathrm{~h}$ in one group of 8 rats, or $12 \mathrm{~h}$ in the other group of 8 rats. Positions of the salts were changed several times. During this time, their water remained in the cage along with the $\mathrm{K}$-deficient food. Figures 6 and 7 show that the $\mathrm{NaCl}$ solution was ingested in greater amounts $(p<.01$, in both conditions unpaired $t$ test).

Calcium deficiency also results in sodium ingestion (Schulkin, 1986; Tordoff, Ulrich, \& Schulkin, 1990). And calcium-deficient rats will barpress to gain access to sodium (Lewis, 1968). In another experiment, a new group of 8 male Sprague-Dawley rats, each $200 \mathrm{~g}$, were used. They were placed on a calcium-deficient diet (Teklad TD 88231) for 2 weeks. At the end of the 2 weeks, the rats were offered the two salts depicted in Figure 8 over a 12-h period (as described). Figure 8 shows that the Na salt was the preferred salt ( $p<.01$, unpaired $t$ test). In earlier experiments, I found similar results with other salts, and control-dieted rats did not show this phenomenon (Schulkin, 1986; but see also Tordoff et al., 1990).

Other mineral deficiencies, such as zinc deficiency (Catalonotto, 1978; Jakinovich \& Osborn, 1981) and iron deficiency (Woods, Vasselli, \& Milam, 1977), also elicit sodium ingestion. In a number of these contexts, the rat

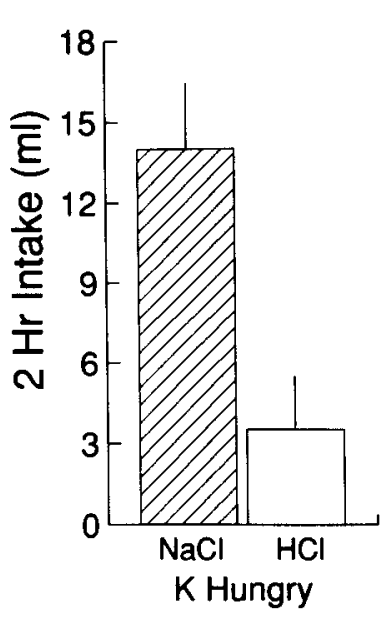

Figure 6. Ingestion of $.12 \mathrm{M} \mathrm{NaCl}$ and $.12 \mathrm{M} \mathrm{HCl}$ in potassiumdeprived rats.

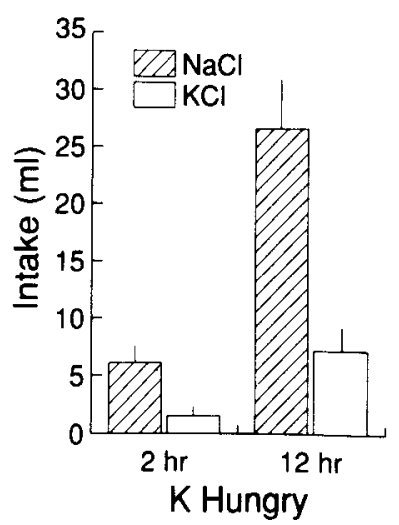

Figure 7. Ingestion of $.15 \mathrm{M} \mathrm{NaCl}$ and $.25 \mathrm{M} \mathrm{KCl}$ in potassiumdeprived rats. 


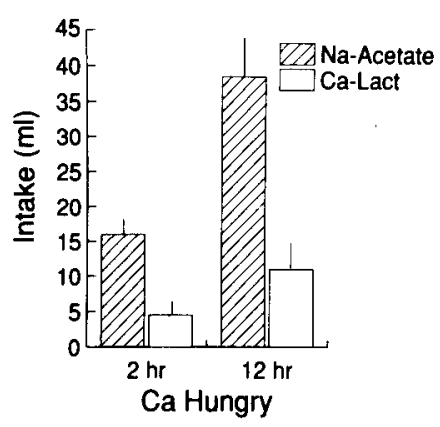

Figure 8. Ingestion of $.15 \mathrm{M} \mathrm{Na}$ acetate and $.15 \mathrm{M}$ Ca lactate in calcium-deprived rats.

would also ingest the mineral that was needed but would tend to ingest the $\mathrm{NaCl}$ (Schulkin, 1986, Figure 8; but see also Tordoff et al., 1990). Rats deficient in Vitamin B and rats fed the control diets did not ingest $\mathrm{NaCl}$ (Schulkin, 1986). Thus, perhaps it is the taste quality of saltiness that is special and alluring to the mineral-deficient rat, and possibly other animals. It is the taste quality that is noticeable at the salt licks; it is what stands out to human observers.

\section{Conclusion}

I have suggested that a reason for the evolution of an innate hunger for sodium, and the alluring properties of saltiness, is the fact that it serves the homeostatic requirement of satisfying mineral requirements. Perhaps, as sweet tastes may signify nutrients (LeMagnen, 1985), salty tastes may signify minerals and bitter tastes may indicate toxins. The significance of sour tastes has not been studied. In each of these cases, the animal uses a taste quality in the maintenance of bodily requirements. In addition, there has long been known to be a water taste (Bartoshuk, 1964); this water taste may serve in the innate hunger and recognition and ingestion of water (Stricker \& Sterritt, 1967). In conclusion, the allure of saltiness may contribute to the organization of the response to mineral deficiency and the ingestion of salt. By having one innate hunger for sodium, motivating the search and ingestion of salt at salt licks, nature may have economized so that other mineral requirements could also be satisfied.

\section{REFERENCES}

ADAM, W. R., \& DAWBorn, J. K. (1972). The effect of potassium depletion on mineral appetite in the rat. Joumal of Comparative and Physiological Psychology, 78, 51-58.

ALDRICH, E. C. (1939). Notes on the salt-feeding habits of the red crossbill. Condor, 66, 30.

Arnell, P., Schulkin, J., Stellar, E. (1988). [Running for salt in male and female rats]. Unpublished raw data.

BARTOSHUK, L. M. (1964). Taste of sodium chloride solutions after adaptation to sodium chloride: Implications for the "water taste." Science, 143, 967-968.

Bartoshuk, L. M. (1980). Sensory analysis of the taste of $\mathrm{NaCl}$. In
M. Kare, M. Fregly, \& R. Bernard (Eds.), Biological and behavioral aspects of salt intake (pp. 83-98). New York: Academic Press.

Bartoshuk, L. M., Murphy, C., \& Cleveland, C. T. (1978). Sweet taste of dilute $\mathrm{NaCl}$ : Psychophysical evidence for a sweet stimulus. Physiology \& Behavior, 21, 609-613.

Berridge, K. C., FlynN, F. W., Schulkin, J., \& Grill, H. J. (1984). Sodium depletion enhances salt palatability in rats. Behavioral Neuroscience, 98, 652-660.

Berridge, K. C., Schulkin, J. (1989). Palatability shift of a saltassociated incentive drive during sodium depletion. Quarterly Journal of Experimental Psychology, 2, 121-138.

BLAKE, W. D., \& JURF, A. N. (1968). Increased voluntary Na intake in $\mathrm{K}$ deprived rats. Communications in Behavioral Biology, A, 1-7.

Bregar, R. E., Strombakis, N., Allan, R. W., \& Schulkin, J. (1983). Brief exposure to saline stimulus promotes latent learning in the salt hunger system. Neuroscience Abstracts.

Catalonotto, F. A. (1978). Effects of dietary methionine supplementation on preferences for $\mathrm{NaCl}$ solutions. Behavioral Biology, 24, 457-466.

Contreras, R. J., Kosten, T., \& Frank, M. E. (1984). Activity in salt taste fibers: Peripheral mechanisms for mediating changes in salt intake. Chemical Senses, 8, 275-288.

Denton, D. (1982). The hunger for salt. New York: Springer-Verlag. DickInson, A., \& NICHOLAs, D. J. (1983a). Irrelevant incentive learning during training on ratio and interval schedules. Quarterly Journal of Experimental Psychology, 35B, 235-248.

Dickinson, A., \& NicholAs, D. J. (1983b). Irrelevant incentive learning during instrumental conditioning: The role of the drive-reinforcer and response-reinforcer relationships. Quarterly Journal of Experimental Psychology, 35B, 249-263.

FALK, J. L. (1965). Limitations to the specificity of $\mathrm{NaCl}$ appetite in sodium-depleted rats. Journal of Comparative \& Physiological Psychology, 60, 393-396.

FUDIM, O. K. (1978). Sensory preconditioning of flavors with a formalinproduced sodium need. Journal of Experimental Psychology: Animal Behavior Processes, 4, 276-285.

Hartzell, A. R., Paulus, R. A., \&chulkin, J. (1985). Brief preoperative exposure of saline protects against behavioral impairments in salt appetite following damage to the central gustatory system. Behavioral Brain Research, 15, 9-13.

Herbert, D., \& Cowan, I. (1971). Natural salt licks as a part of the ecology of the mountain goat. Canadian Joumal of Zoology, 49, 605-610.

HILL, D. L. (1988). Influences of dietary sodium on functional taste receptor developmental sensitive period. Science, 241, 1826-1828.

Hoffman, R. A., \& Robinson, P. F. (1966). Changes in some endocrine glands of white-tailed deer as affected by season, sex and age. Journal of Mammalogy, 47, 266-280.

JACOBS, K. M., MARK, G. P., \& SCOTT, T. R. (1988). Taste responses in the nucleus tractus solitarius of sodium-deprived rats. Journal of Physiology, 406, 393-410.

JAKINOVICH, W., JR., \& OSBORN, D. W. (1981). Zinc nutrition and salt preference in rats. American Journal of Physiology, R223-R229.

Jalowiec, J. E., Crapanzano, J. E., Stricker, E. M. (1966). Specificity of salt appetite elicited by hypovolemia. Psychonomic Science, 6, 331-332.

Jones, R. L., \& HaNson, H. C. (1985). Mineral licks, geophagy, and biogeochemistry of North American ungulates. Ames: Iowa State.

Krecek, J., Novakova, V., \& Stibral, K. (1972). Sex differences in the taste preference for a salt solution in the rat. Physiology \& Behavior, 8, 138-188.

KriECKhaUs, E. E. (1970). "Innate recognition" aids rats in sodium regulation. Journal of Comparative \& Physiological Psychology, 73, 117-122.

KrieckHaus, E. E., \& Wolf, G. (1968). Acquisition of sodium by rats: Interaction of innate mechanisms and latent learning. Journal of Comparative \& Physiological Psychology, 65, 197-201.

LeMAGnen, J. (1985). Hunger. New York: Cambridge University Press. LEWIS, M. (1968). Discrimination between drives for sodium chloride 
and calcium. Journal of Comparative \& Physiological Psychology, 65, 208-212.

Nachman, M. (1963). Taste preferences for lithium chloride by adrenalectomized rats. American Joumal of Physiology, 205, 219-221.

Nitabach, M., Spector, G., \& Grill, H. J. (1988). Gustatory identification of sodium ions is dependent on the chorda tympani innervation of the rat tongue. Neuroscience Abstracts, 14, 1063.

Paulus, R. A., Eng, R., Schulkin, J. (1984). Preoperative latent place learning preserves salt appetite following damage to the central gustatory system. Behavioral Neuroscience, 1984, 98, 146-151.

Peterson, J. G. (1942). Salt feeding habits of the house finch. Condor, 44, 73.

Rescorla, R. A., \& Freeburg, L. (1978). The extinction of withincompound flavor associations. Leaming \& Motivation, 9, 411-427.

Richter, C. P. (1956). Salt appetite in mammals: Its dependence on instinct and metabolism. In E. Masson (Ed.), L'instinct dans le comportement des animaux et de l'homme (pp. 577-629). Paris: Masson.

Rozin, P., \&chulkin, J. (1990). Food selection. In E. Stricker (Ed.), The handbook of behavioral neurobiology (pp.297-328). New York: Plenum.

Sakai, R. R., Frankmann, S. P., Fine, W. B., \& Epstein, A. N. (1989). Prior episodes of sodium depletion increase the need-free sodium intake of the rat. Behavioral Neuroscience, 103, 186-192.

Schulkin, J. (1982). Behavior of sodium deficient rat: The search for a salty taste. Journal of Comparative \& Physiological Psychology, 96, 628-624.

SCHULKIN, J. (1986). The evolution and expression of salt appetite. In G. deCaro, A. N. Epstein, \& M. Massi (Eds.), The physiology of thirst and sodium appetite (pp. 491-496). New York: Plenum.

SchulkIN, J. (1991). Sodium hunger: The search for a salty taste. Cambridge: Cambridge University Press.

Schulkin, J., Arnell, P., \& Stellar, E. (1985). Running to the taste of salt in mineralocorticoid-treated rats. Hormones \& Behavior, 19 , 413-425.
Schulkin, J., ARnell, P., \& Stellar, E. (1986). [Salt-lick ingestion]. Unpublished data.

Schulkin, J., Leibman, D., Ehrman, R. N., Norton, N. W., \& TERNES, J. W. (1984). Salt hunger in the rhesus monkey. Behavioral Neuroscience, 98, 753-756.

Stellar, E., Hyman, R., SAmet, S. (1954). Gastric factors controlling water and salt solution drinking. Journal of Comparative \& Physiological Psychology, 47, 220-226.

Stricker, E. M., Sterritt, G. M. (1967). Osmoregulation in the newly hatched domestic chick. Physiology \& Behavior, 2, 117-119.

Tordoff, M. G., Ulrich, P. M., \& Schulkin, J. (1990). Calcium deprivation increases salt intake. American Joumal of Physiology, 259. R411-R419.

VAN HEMEL, P. E. (1976). Ingestion of potassium chloride and sodium chloride solution by albino and hooded rats. Behavioral Biology, 17, 519-537.

Wirsig, C. R., \&RILL, H. J. (1982). Contribution of the rat's neocortex to ingestive control: 1 . Latent learning for the taste of sodium chloride. Journal of Comparative \& Physiological Psychology, 96, 615-627.

WoLF, G. (1969). Innate mechanisms for regulation of sodium intake. In C. Pfaffman (Ed.), Olfaction and taste (pp. 548-553). New York: Rockefeller University Press.

WOLF, G. (1982). Refined salt appetite methodology for rats demonstrated by assessing sex differences. Joumal of Comparative \& Physiological Psychology, 96, 1016-1021.

Woods, S. C., VASSELLI, J. R., \& Milam, K. M. (1977), Iron appetite and latent learning in rats. Physiology \& Behavior, 19, 623-626.

(Manuscript received February 1, 1991; revision accepted for publication April 4, 1991.) 